\title{
A Giant Calcified Subdural Empyema, a Complication of Ventriculo Peritoneal Shunt: Surgical Management and Revue of Literature
}

\section{Faye Mohameth ${ }^{1,2 *}$, Diop Abdoulaye1, Kissao Nissao', Roger Ilunga Mulumba², Djasde Donald², Badiane Seydou Boubacar ${ }^{2}$}

${ }^{1}$ Neurosurgery Departement of El Hadj Ahmadou Sakhir Ndieguene's Regional Hospital, Thies, Senegal

${ }^{2}$ Neurosurgery Departement of CHU FANN, Dakar, Senegal

Email: ${ }^{\star}$ fayeneurochir92@gmail.com

How to cite this paper: Mohameth, F., Abdoulaye, D., Nissao, K., Mulumba, R.I., Donald, D. and Boubacar, B.S. (2020) A Giant Calcified Subdural Empyema, a Complication of Ventriculo Peritoneal Shunt: Surgical Management and Revue of Literature. Open Journal of Modern Neurosurgery, 10, 203-207.

https://doi.org/10.4236/ojmn.2020.102021

Received: December 21, 2019

Accepted: February 14, 2020

Published: February 17, 2020

Copyright $\odot 2020$ by author(s) and Scientific Research Publishing Inc. This work is licensed under the Creative Commons Attribution International License (CC BY 4.0).

http://creativecommons.org/licenses/by/4.0/

\begin{abstract}
Subdural empyema is not a usual complication of ventriculo peritoneal shunt and the discovery of his calcified form is much exceptional in young adults. We report the case of a female patient of 17 years old carrying a shunt since 16 years who was received for retro auricular suppuration facing the intra ventricular drain and whom cerebral CT-Scan shows a right hemispheric calcified empyema. A large craniotomy was realized in the same time than an external ventricular drain. Evolution was marked by minor right body motor troubles and seizures. Difficulties we have faced during the management are a reminder about morbidity due to the insertion of a ventriculo peritoneal shunt and the need of and long term follow up for the carriers.
\end{abstract}

\section{Keywords}

Giant Calcified Empyema, Ventriculo Peritoneal Shunt

\section{Introduction}

Subdural empyema represents $13 \%$ to $25 \%$ of intracranial bacterial infection [1]. It realizes an extra cerebral suppurated collection which can be clinically expressed by seizures, focal neurological deficit and sometimes infectious syndrome [2]. If in most cases, it results from neighborhood infections through the emissary veins, it can be a brain surgery complication [3]. Ventriculo peritoneal shunt is the standard treatment in malformative hydrocephalus and realizes a communication between ventricles and peritoneal cavity. Infectious complications are found in between $2 \%$ and $10 \%$ of the case, however, empyema is a rare 
complication of ventriculo peritoneal shunt [4]. Chronic calcified subdural empyemas are extremely rare [5]. Although it is difficult in anatomopathological, clinical and radiologic levels to differentiate them from subdural calcified hematomas, this work represents the second publication about chronic calcified empyema following a ventriculo peritoneal shunt in young adults.

\section{Case Presentation}

A 17 years old female patient was seen on October $8^{\text {th }} 2019$ for right retro auricular suppuration evolving since one month. She was complaining for headaches vomiting and chills since 3 months without improvement under analgesic treatment. She carries a ventriculo peritoneal shunt since she is 7 months old for malformative hydrocephalus.

On examination she was conscious with light slowness, brisk deep tendon reflexes in all limbs. We notice $62 \mathrm{~cm}$ for head circumference and a suppurated retro auricular puncture wound facing ventricular drain. Furthermore the ventriculo peritoneal shunt reservoir was depressible.

The cerebral CT-Scan sequence without contrast was showing a right hemispheric isodense image with internal and peripheral hyperdensity corresponding to calcification and the sequence with contrast almost shown the same lesions. However we notice an important mass effect on median structures and intraventricular catheter presence (Figure 1). The blood test found an inflammatory syndrome with raised C-reactive protein elevated at $14.2 \mathrm{mg} / \mathrm{L}$.

The diagnosis of a right hemispheric giant calcified empyema which complicates a ventriculo peritoneal shunt was made and a large craniotomy associated with an extra ventricular drain after ventriculo peritoneal shunt removal was then performed.

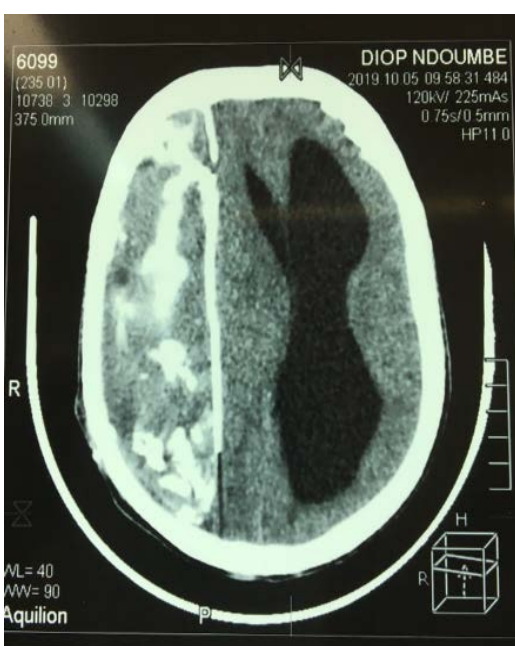

(a)

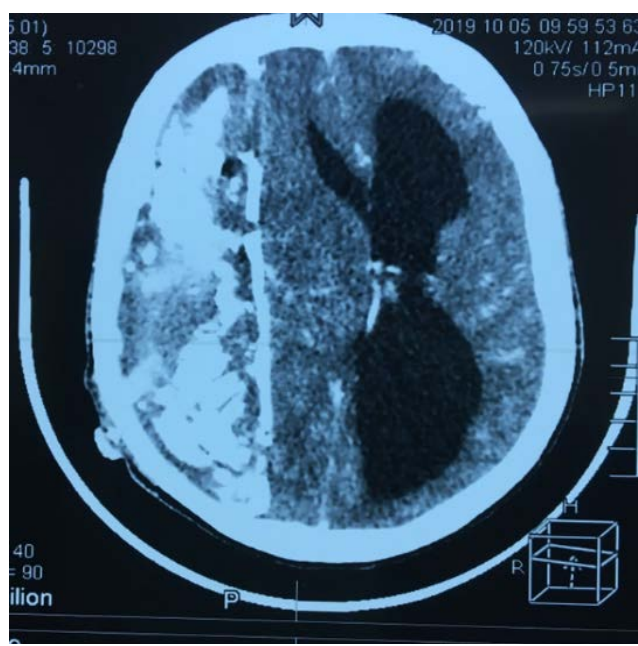

(b)

Figure 1. Preoperative without contrast CT scan (a) showing an isodense right hemispheric lesion with internal hyperdensity and midline shift with right hemisphere displacement (b). 
Craniotomy concerned the right hemisphere and discovered a thickened dura mater covered in his internal face by calcareous deposits. His opening shows a pasty greenish yellow pus which hardly come by suction. It finally remains a thickened calcareous wall pressed against the external surface of the brain. We hardly take off by fragmentation.

Even though the drain tip culture and pus was sterile a double antibiotherapy based on Third Generation Cephalosporin and imidazole was initiated for 3 weeks.

Immediately in postoperative, the patient presented right hemiparesis (estimated to 4/5 on Medical Research Council scale) and seizures which require physical therapy and phenobarbital prescription that lead to complete deficit resolution and seizures regression a month after surgery.

Control CT-Scan realized 8 days after surgery show right hemispheric reexpansion and mass effect reduction (Figure 2).

\section{Discussion}

Subdural giant calcified empyema due to a ventriculo peritoneal shunt realized 16 years ago is exceptional. Its etiopathogenesis is not totally mastered. We related it to bloodshed during the ventriculo peritoneal shunt placement contamined by subclinical meningitidis. The onlysimilar case was described ten years ago in India by Kasliwal and $\mathrm{Al}$ in a female patient of 17 years old who carries aventriculo peritoneal shunt since 10 years with the same etiopathogenesis [6]. The infection secondary progress to the scalp by contiguity.

Process of calcification in subdural empyema as in sudural hematoma isn't well known. This process takes 3 to 12 month after pus constitution and is influenced by local factor as blood stase associated to venous drainage default [7]. Boyd and Merrel think in addition that it exist metabolic predisposition to

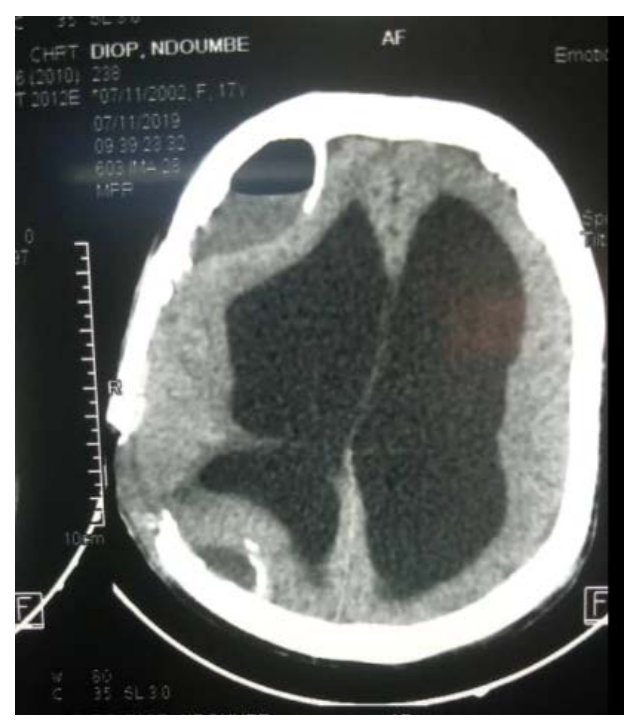

Figure 2. Post operative CT scan showing brain volume reexpansion. 
calcification correlate to connective tissue thickness [8].

The contrast between imagery results and the relative conservated clinical state testimony of the insidious character of this complication and present a therapeutic issue. Indeed after the ossification stade, those lesions stop to grow and some author discuss the necessity of surgery [9] [10]. Surgery was motivated by intracranial hypertension sign and dermal suppuration.

Partial right hemicorpus deficit and seizures are linked to cortical irritation during surgery.

\section{Conclusion}

The cause of giant subdural calcified empyema as complication of ventriculo peritoneal shunt is not totally mastered. It has a slow and insidious evolution that can hide the gravity of brain damage. Seizure and motor disorders can complicate its removal surgery.

\section{Acknowledgements}

We thank everyone who participated in the development of this work.

\section{Conflicts of Interest}

On behalf of all author, the corresponding author states that there is no conflict of interest.

\section{Authors' Contribution}

Conception and design: Mohameth FAYE: fayeneurochir92@gmail.com, Diop Abdoulaye: balaye82@hotmail.fr.

English grammar: Kissao NISSAO: kissaojoel@gmail.com and Djasde Donald: Donald.djas@gmail.com.

Manuscript writing: Mohameth FAYE: fayeneurochir92@gmail.com, Roger Ilunga Mulumba: rogermulumba2004@gmail.com.

Final approval of manuscript: Seydou Boubacar Badiane: seybadiane@gmail.com.

\section{References}

[1] Thiam, A.B. and Badiane, S.B. (2017) Empyèmes intracraniens: Infection de la sous-médicalisation. Editions Universitaires européEnnes, p. 10.

[2] Bhandari, Y.S. and Sarkari, N.B. (1970) Subdural Empyema: Review of 37 Cases. Journal of Neurosurgery, 32, 35-39. https://doi.org/10.3171/jns.1970.32.1.0035

[3] Leys, D. (2001) Abcès cérébraux et empyèmes intracrâniens. Encycl Méd Chir (Editions Scientifiques et Médicales Elsevier SAS, Paris) Neurologie, 17-485-A-10, 7 p.

[4] Edwards, N.C., Engelhart, L., Casamento, E.M. and McGirt, M.J. (2015) Cost-Consequence Analysis of Antibiotic-Impregnated Shunts and External Ventricular Drains in Hydrocephalus. Journal of Neurosurgery, 122, 139-147. https://doi.org/10.3171/2014.9.JNS131277

[5] Kaspera, W., Bierzynska-Macyszyn, G. and Majchrzak, H. (2005) Chronic Calcified 
Subdural Empyema Occurring 46 Years after Surgery. Neuropathology, 25, 99-102. https://doi.org/10.1111/j.1440-1789.2004.00592.x

[6] Kasliwal, M.K., Sinha, S., Kumar, R. and Sharma, B.S. (2009) Giant Hemicranial Calcified Subdural Empyema-Unusual Complication Following Ventriculoperitoneal Shunt Insertion. The Indian Journal of Pediatrics, 76, 651-652.

https://doi.org/10.1007/s12098-009-0162-6

[7] Debois, V. and Lombaert, A. (1980) Calcified Chronic Subdural Hematoma. Surgical Neurology, 14, 455-458.

[8] Boyd, D.A. and Merrell, J.P. (1943) Calcified Subdural Hematoma. The Journal of Nervous and Mental Disease, 98, 609-617.

https://doi.org/10.1097/00005053-194312000-00003

[9] Watts, C. (1976) The Management of Intracranial Calcified Subdural Hematomas. Surgical Neurology, 6, 247-250.

[10] Waga, S., Sakakura, M. and Fujimoto, K. (1979) Calcified Subdural Hematoma in the Elderly. Surgical Neurology, 11, 51-52. 